\title{
Palliative care: A proposal for undergraduate education in Medicine
}

Gustavo Henrique de Oliveira Caldas'

Simone de Nóbrega Tomaz Moreira'

Maria José Vilar'

\section{Abstract}

Objective: to propose essential competencies for the teaching of palliative care on undergraduate Medicine courses. Method: a documentary analysis of the literature on general competencies in palliative care was initially carried out, to construct a framework with suggestions of essential competencies for undergraduate education in Brazil. The elaborated material was then presented individually to eight professionals from a range of areas for analysis. All the professionals had specialized training in palliative care, and the material was accompanied by an interview with three open questions. The categorical thematic content analysis proposed by Bardin was used in the documentary analysis and the interviews with the professionals. Results: the initial documentary analysis resulted in five categories, eight subcategories and 96 units of analysis, based on which the researcher was able to construct the suggestions for competences, which were distributed with their respective contents in a framework with five modules. Six categories, 12 subcategories and 168 analysis units emerged from the interviews with the

\section{Keywords: Palliative} Care. Palliative Medicine. Education, Medical. Curriculum. Qualitative Research.

\footnotetext{
Universidade Federal do Rio Grande do Norte, Centro de Ciências da Saúde, Departamento de Medicina Clínica, Programa de Pós-graduação em Ensino na Saúde, Hospital Universitário Onofre Lopes. Natal, Rio Grande do Norte, Brasil.
} 


\section{INTRODUCTION}

The acquiring of competencies and broadening of knowledge in palliative care is of great importance due to the large number of people with diseases that threaten the continuity of life and who require care that goes beyond controlling the actual symptoms of disease and which involves psychosocial and spiritual care and the paying of proper attention to family members. These are the basic principles of palliative care, which stem from a modality of care directed at individuals in the initial stage of progressive, advanced and incurable disease ${ }^{1}$. Within the perspective of this article competencies consist of the integration of knowledge, skills and attitudes that can be used to successfully perform a professional task ${ }^{2}$.

One of the earliest attempts to publish a curriculum for the teaching of palliative care at undergraduate level took place in Canadian medical schools in 1993. The American Academy for Hospice and Palliative Medicine subsequently published a core curriculum in $1998^{2}$.

The European Association for Palliative Care (EAPC) established a summary of a proposed curriculum, setting out the minimum of knowledge and skills that a medical student should acquire during his/her undergraduate course ${ }^{3}$.

In 2008 the Société Canadienne des Médecins des Soins Palliatifs proposed six items in which to divide competencies: medical expertise in pain and other symptoms, medical expertise in psychosocial and spiritual needs, and the roles of administrator, communicator, collaborator and promoter of health ${ }^{4}$. Subsequently, similar projects were implemented in Japan, the United Kingdom and Colombia ${ }^{5-7}$.

In Brazil, the Universidade Federal de São Paulo was the first medical school to offer Palliative Care courses on an elective basis to undergraduate students in Medicine, between 1994 to 2008. In 2003, a compulsory Palliative Care discipline was created at the Universidade de Caxias do Sul ${ }^{8}$.

Despite these examples of approaches to palliative care in education, which were later followed by other universities, there is a lack of correlation between the provision of instruction in palliative care and the perception of its importance in most medical schools. Such schools have described insufficient time, a lack of faculty expertise and the time-consuming demands of multiple interests as the reasons for the lack of curricular under-representation of palliative care?

Yet by placing the student in contact with palliative care during training we can help to improve patient care. This study therefore aimed to propose essential skills for the teaching of palliative care in undergraduate courses in Medicine.

\section{METHOD}

A descriptive, exploratory, qualitative study was carried out. Data was obtained through documentary analysis and a case study based on an interview with three open questions. Data was evaluated through the analysis of categorical thematic content based on the dismemberment of the text into units and categories according to analog regroupings, as described by $\operatorname{Bardin}^{10}$.

Documentary analysis was carried out from January to February 2017, based on the selection by the principal researcher of six relevant scientific articles on the topic ${ }^{5-7,11-13}$, two books on palliative care $^{2,14}$ and recommendations of online material of the websites of the following international institutions: the European Association for Palliative Care, the Société Canadienne des Médecins de Soins Palliatifs, the Australian Government Department of Health through the Palliative Care Curriculum for Undergraduates (PCCAU) and the American Association of Hospice and Palliative Medicine (AAHPM) $)^{3,4,15,16}$. The core competencies in palliative care of the AAHPM ${ }^{16}$ were used in the documentary analysis as this is considered an important document for basic knowledge, although it is acknowledged that more complex competencies are required for undergraduate study.

After the creation of the documentary corpus, exhaustive readings were carried out from which the categories, subcategories and units of analysis emerged on an aposteriori basis $^{10}$. When the exploration of the sources became redundant, based on a sense of the integration of the information obtained, the search for new sources was interrupted ${ }^{17}$. Thus, using 
Bloom's Taxonomy ${ }^{18}$ for clarity in the understanding of the educational objectives, a suggestion of essential competencies for the teaching of palliative care on medical undergraduate courses was created (Table 1).

In the case study section, eight professionals were interviewed individually (three physicians, one nurse, three psychologists and one occupational therapist) between February and March of 2017, in their places of work. The choice of the professionals participating in the research was based on their training in palliative care and having at least two years of practice in the area. Six professionals had worked in undergraduate or postgraduate courses while two were palliative care professionals with information acquired through practical experience. The total of eight participants was defined by the saturation technique ${ }^{19}$.

The material with the suggestions for competencies created by the researcher was given to each of the interviewees, who were then informed that these skills could be acquired at any time on the course, depending on the methodology and peculiarities of each course (Table 1). The interview was composed of three open questions: 1) How would you improve the competencies in palliative care in undergraduate medical teaching described in the material delivered to you?; 2) Comment on the importance of an interprofessional approach to teaching in palliative care, emphasizing the biological, psychological, social and spiritual dimensions of care; 3) Talk about the obstacles to the implementation and development of the proposal in undergraduate teaching in Medicine.

For the analysis of the data, the recorded interviews (two hours and fifty minutes) were transcribed and 26 pages of information were obtained. The interviewees were identified in random order and in sequence, starting with I1.

Following an exhaustive reading of the material for a better understanding, the corpus was created and the categorization process began, in this case on an a priori basis, from which the categories, subcategories and units of analysis emerged, which will be discussed using the theoretical reference ${ }^{10}$.

Following approval by the Research Ethics Committee of the Hospital Universitário Onofre Lopes (CEP-HUOL), dated January 27, 2017 and under approval number 1,900,460, the study began. All interviewees invited to participate signed a Free and Informed Consent Form.

\section{RESULTS AND DISCUSSION}

Table 1 describes the documentary analysis that resulted in five categories, eight subcategories and 96 units of analysis.

Table 1. Categories, subcategories and units of analysis obtained during the documentary analysis, from the analysis of categorical thematic content. Natal, Rio Grande do Norte, 2017.

\begin{tabular}{l|l|l}
\hline Categories & Subcategories & Unit of analysis (n) \\
\hline \multirow{2}{*}{ Introduction } & Concepts, recommendations and epidemiological context & 11 \\
\cline { 2 - 3 } Symptom control & Anamnesis, communication and physical examination & 15 \\
\hline Interprofessional team & Classification, evaluation and treatment of symptoms & 18 \\
\hline \multirow{2}{*}{$\begin{array}{l}\text { Topics in Palliative Care } \\
\text { Assistance in the final moments } \\
\text { of life }\end{array}$} & Dynamics of interprofessional relations & 11 \\
\cline { 2 - 3 } & Ledical Specialties in Palliative Care & 3 \\
\cline { 2 - 3 } & End of life care & 14 \\
\hline
\end{tabular}


Following this analysis, a suggestion of essential competencies for the teaching of palliative care in medical undergraduate courses was created (Chart 1). The categories and sub-categories guided the core competencies, which were divided into five modules. The units of analysis guided the content.
Table 2 shows the case study analysis of the transcribed material of the recordings obtained in the interviews, based on the categorization process, which resulted in six categories, 12 subcategories and 168 analysis units.

Chart 1. Suggestion of competencies in palliative care for undergraduate medical courses presented to the interviewees by the researcher. Natal, Rio Grande do Norte, 2017.

\begin{tabular}{|c|c|}
\hline Competencies & Content \\
\hline $\begin{array}{l}\text { The student should be able to: } \\
\text { - Understand definitions, principles and indications for } \\
\text { palliative care. } \\
\text { - Understand the geographical distribution of palliative } \\
\text { care services. } \\
\text { - Perform patient care in palliative care and develop a } \\
\text { care plan. } \\
\text { - Understand the steps of the SPIKES protocol in } \\
\text { communicating bad news. } \\
\text { - Understand the functioning of the various palliative } \\
\text { care services. }\end{array}$ & $\begin{array}{l}\text { Module I - Introduction: } \\
\text { - Definition and principles. } \\
\text { - Geographic distribution of palliative care services in } \\
\text { Brazil and around the world. } \\
\text { - Anamnesis, physical examination and planning of care } \\
\text { in palliative care. } \\
\text { - Communication in palliative care. } \\
\text { - Palliative care services. }\end{array}$ \\
\hline $\begin{array}{l}\text { The student should be able to: } \\
\text { - Evaluate pain and identify the correct pharmacological } \\
\text { and non-pharmacological treatment. } \\
\text { - Evaluate dyspnea, coughing, nausea and vomiting and } \\
\text { know the proper treatment. } \\
\text { - Assess constipation, diarrhea, delirium, depression, } \\
\text { anxiety and know the proper treatment. } \\
\text { - Understand and provide care in controlling the } \\
\text { symptoms of major emergencies in palliative care. }\end{array}$ & $\begin{array}{l}\text { Module II - Symptom Control: } \\
\text { - Classification, evaluation and treatment of pain. } \\
\text { - Evaluation and treatment of dyspnea, cough, nausea, } \\
\text { vomiting. } \\
\text { - Evaluation and treatment of constipation, diarrhea, } \\
\text { delirium, depression and anxiety. }\end{array}$ \\
\hline $\begin{array}{l}\text { The student should be able to: } \\
\text { - Understand the dynamics of interprofessional relations. }\end{array}$ & $\begin{array}{l}\text { Module III - Interprofessional team: } \\
\text { - Physician, nurse, psychologist, nutritionist, } \\
\text { physiotherapist, speech therapist and occupational } \\
\text { therapist, social worker and pharmacist. }\end{array}$ \\
\hline $\begin{array}{l}\text { The student should be able to: } \\
\text { - Understand and technically apply hypodermoclysis. } \\
\text { - Understanding oral health care in patients in palliative } \\
\text { care. } \\
\text { - Differentiate concepts in bioethics, addressing } \\
\text { bioethical themes related to the termination of life. } \\
\text { - Understand the anticipated directives and their } \\
\text { implications on the patient's reality. } \\
\text { - Know the importance of Brazilian legislation in the } \\
\text { historical process of consolidation of palliative care. } \\
\text { - Understand the applicability of palliative care across a } \\
\text { range of specialties. }\end{array}$ & $\begin{array}{l}\text { Module IV - Topics in Palliative Care: } \\
\text { - Hypodermoclysis - subcutaneous route. } \\
\text { - Care of the oral cavity. } \\
\text { - Orthothanasia, euthanasia, mysthanasia, dysthanasia. } \\
\text { - Living will - advance directives. } \\
\text { - Code of medical ethics and Brazilian legislation in } \\
\text { relation to palliative care. } \\
\text { - Palliative care in pediatrics. } \\
\text { - Palliative care in geriatrics. }\end{array}$ \\
\hline $\begin{array}{l}\text { The student should be able to: } \\
\text { - Identify the last } 48 \text { hours of life, based on its most } \\
\text { frequent symptoms. } \\
\text { - Understand the definition of palliative sedation, as well } \\
\text { as when it is recommended. } \\
\text { - Understand the prospect of terminality in different } \\
\text { religions, as well as support for the family in the grief } \\
\text { phase. }\end{array}$ & $\begin{array}{l}\text { Module V - Care in the last moments of life: } \\
\text { - The last } 48 \text { hours of life. } \\
\text { - Palliative sedation. } \\
\text { - Grief: support life and the patient. } \\
\text { - Spirituality, religions, culture, terminality. }\end{array}$ \\
\hline
\end{tabular}


Table 2. Categories, subcategories and units of analysis obtained from the categorical thematic content analysis of the discourse of the interviewees on the suggestion of competencies in palliative care in undergraduate teaching in Medicine. Natal, Rio Grande do Norte, 2017.

\begin{tabular}{|c|c|c|}
\hline Categories & Subcategories & Analysis unit (n) \\
\hline 1. Basic principles of palliative care & 1.1. Overall assessment of the patient & 9 \\
\hline \multirow[b]{2}{*}{ 2. Management of symptoms } & 2.1. Expanding symptom management & 10 \\
\hline & $\begin{array}{l}\text { 2.2. Insertion of palliative care in related } \\
\text { clinical areas }\end{array}$ & 7 \\
\hline 3. Ethical and legal issues & 3.1. The importance of bioethics & 11 \\
\hline \multirow{2}{*}{$\begin{array}{l}\text { 4. Communication and psychosocial } \\
\text { and spiritual aspects }\end{array}$} & 4.1. Communication of bad news & 11 \\
\hline & 4.2. Process of grief & 10 \\
\hline 5. Teamwork & 5.1. Interprofessionality in clinical practice & 30 \\
\hline \multirow{5}{*}{$\begin{array}{l}\text { 6. Challenges for the implementation } \\
\text { of the proposal }\end{array}$} & 6.1. Did not know about palliative care & 10 \\
\hline & 6.2. Professor's lack of specialized knowledge & 10 \\
\hline & 6.3. Resistance to change and bureaucracy & 21 \\
\hline & 6.4. Excessive curricula workload & 25 \\
\hline & $\begin{array}{l}\text { 6.5. Limited resources for investments in } \\
\text { undergraduate education }\end{array}$ & 14 \\
\hline
\end{tabular}

There is an increasing need to define the competencies in palliative care in medical undergraduate teaching in Brazil. We will now present and discuss some of the statements of the interviewees, based on the sequence of categories presented in Table 2.

In the Basic Principles of Palliative Care category, the statements agreed with the organization of module 1, "Introduction". Some of the speakers stressed the need to move towards a more overall assessment of the patient as a requirement in the area of palliative care:

"Congratulations on what you have created! The
sequence is very logical. But you've put anamnesis
and physical exams in Module 1, and it's a little
more than that. It's about getting to know the
patient through an overall assessment." (I8).

In this discourse, referring to the overall assessment of palliative care patients, it was observed that professionals referred much more frequently to the way in which the content is developed than to actual changes in what was presented to them.

The need to evaluate the patient in an overall manner has already been discussed in literature which discusses the value of the individuality of patients, facilitating a relationship where the patient feels comfortable sharing information about the chronology of the evolution of their disease and treatment already performed, which can help doctors understand the evolution and prognosis of the condition and their expectations about the proposed treatment ${ }^{20}$.

The main suggestions of the interviewees in the symptom management category emphasized the importance of palliative care in different medical specialties, clearly identifying the expansion of palliative care in recent years, in which it has reached several areas, as can be seen in the discourses below:

\footnotetext{
"Students need to understand that the definition and principles of palliative care have a certain basic element, but when they are faced with a neurological patient, or an elderly patient, or a cancer patient, they will use slightly different things, their reasoning needs to be a bit different, the natural history of the disease is a bit different." (I6).
}

A recent study on the definition of competencies in palliative care for physicians emphasized the emergence of acquiring skills in the areas of 
cardiology, pneumology, gastroenterology and pediatrics, or in other words clinical segments which until recently were not closely considered for the palliative approach ${ }^{13}$. One interesting suggestion of the interviewees was the need to undo the idea that only areas such as oncology and geriatrics deal with palliative care. As we are proposing competencies for undergraduate students, however, this theme should be approached in a manner that contemplates the generalist training under discussion, but in a selective manner.

The importance the interviewees gave to the topic was evident in the category Ethical and legal issues, to the extent that they suggested the creation of a specific module on bioethics and legislation, as can be seen in the following statements:

"We could create a specific module of bioethics (I have sometimes seen them in in different units) and legislation in palliative care ... I think this part of the legislation would be very important." (I1).

"I would take the part of module IV about hypodermoclysis and the part of understanding oral health care and put it all together here (Unit II) and leave only the concepts related to bioethics in Module IV. I think it would be more interesting." (I4).

The importance of these two themes (palliative care and bioethics) has already been addressed in other scientific articles, including in Brazilian studies, highlighting their importance for the development of relational skills, which is vital for the care of patients with advanced and terminal disease ${ }^{21}$. Knowledge of Brazilian legislation in the area of palliative care and on the ethical duties of the Brazilian doctor is weak, according to a recent study, ${ }^{22}$ as the vast majority of respondents did not mention anything about respecting the patient's autonomy or informing them about the diagnosis and prognosis of their disease, as defined by the Brazilian Code of Medical Ethics ${ }^{22}$.

The discourses in the present study also revealed relevant suggestions in the category Communication and psychosocial and spiritual aspects for the amplification of techniques of communication, as well as for the entire process of grief and death from a psychosocial and spiritual point of view:

\begin{abstract}
"On the issue of communication, you can focus much more on the SPIKES protocol, to make it clear that the what you're doing is not rigid. Of course it can serve as a guide. It would not be a suggestion for a fixed protocol, but techniques of approach.” (I7).

"I noticed that death itself wasn't mentioned, the conception of death, the difficulty of speaking about death. The difficulties that the family and the patient will face in relation to palliative care will be based on our paradigms regarding death..." (I7).

"This anticipatory grief is for the family, the patient, and the team. I think we can expand here. Talking about grief in the post-death phase is aimed at relatives, because it is also part of the guidelines that support the bereaved family." (I4).
\end{abstract}

According to a recent study, mastery of communication skills enables physicians to be more capable of demonstrating sensitivity, honesty and compassion in difficult communication situations such as those involving death, adverse events at the end of life, bad news and other sensitive topics ${ }^{23}$. As such, communication in palliative care involves a complex mix of spiritual, social, psychological and physical issues in the context of the process of death, resulting in greater dissatisfaction with the care received in the case of ineffective communication ${ }^{24}$. A competency-based training program in palliative care should always aim at continuous professional development and especially communication ${ }^{25}$.

The study also highlights the need for discussion, in the area of palliative care, of topics such as: the transmission of bad news, dealing with the approach of death, anticipatory grief, and the grief of family members ${ }^{23}$. These issues were identified in our study as difficulties for the professionals when talking with patients about the aggravation of disease and the possibility of death, as well as the feeling of impotence that these situations provoke.

Interprofessional teamwork, one of the assumptions of palliative care, requires that each of the professionals involved has the ability to communicate with professionals from other areas of knowledge. It is important to understand one's own work and at the same time understand the activities of other 
team professionals. These concepts were addressed by the interviewees, who emphasized the importance of interprofessional work in the construction of palliative care competencies, which we grouped in the category Teamwork, as described below:

"You can't carry out palliative care alone! From a conceptual point of view, interprofessional care has to be part of the routine of palliative care. It's difficult for us, as just doctors, like any other professional in the team, to act without the help of everyone else." (I1).

Interprofessional education is understood as an intervention where members of more than one health or social professional area learn by interacting together, aiming to improve interprofessional collaboration and the well-being of patients ${ }^{26}$. In this sense, interprofessional education, according to the references consulted, can only be achieved if educators are willing to be flexible, creative and persistent, displaying mutual respect, valuing each professional area and each member of the interdisciplinary team, with transparent and open communication, shared leadership and the inclusion of the patient and caregiver in the interprofessional team $^{27}$.

The discourses below acknowledge the need for education and interprofessional teamwork:

"The doctor's problem is that he knows how to work with this team, but there is a lack of teamwork, so the doctor knows that he will not be able to provide all the care the patient requires." (I3).

"Today we know that a palliative care team, according to some authors, includes a palliative physician, a nurse, a psychologist, a social worker with the support of a chaplain, an occupational therapist, a nutritionist, a pharmacist, then you have interprofessional work.” (I5).

It is essential, therefore, that in order to achieve excellence in such care, there should be a team of interdisciplinary and interprofessional scope, whose level of dedication will be quantified according to the concrete needs of care ${ }^{28}$. When professionals from different areas work together but do not bring knowledge of their specialized work to the team, however, it represents a lack of teamwork ${ }^{28}$.

Some interviewees addressed the need to cross theoretical concepts, seeking to improve student learning through different health professionals:

"It is important to have theoretical content about the role of professionals, but students should not only spend time with the medical team, but also experience the practices of other professionals, even if only briefly." (I6).

Historically, students learn about palliative care through course readings and content, but this content is best taught through practical experience ${ }^{29}$. While it is not easy to incorporate clinical exposure and faceto-face learning with other professions into crowded curricula, recently published research confirms the benefits of such inclusion ${ }^{29}$.

However, research highlights the difficulties of implementing these proposals in a country with a marked uni-professional division of labor in health services and a strong culture of hierarchy among different professions. Thus, there are few opportunities to work collaboratively, and to develop high-quality, patient-centered palliative care ${ }^{26,30}$.

The conceptual ignorance of palliative care among a number of professionals was cited as the most important obstacle to be overcome to improve the teaching of such care, as verified in the statements below, which were grouped in the category Challenges for the implementation of the proposal:

"First of all there is a lack of knowledge, few professionals with the ability to manage, to take responsibility. There might be interest, but few who take the initiative." (I2).

"The vast majority of lecturers, professors and directors don't think it is not important. If it is inside a hospital, the director thinks what they say in the universities isn't important. It's not that there's no knowledge base, it's that no one knows what it even is. There is a lack of general knowledge of the subject. Even before there is resistance to the idea, there is a lack of knowledge of what it is." (I3). 
Studies in other countries show that the lack of knowledge about palliative care among health professionals was perceived as an additional barrier to the development of the area and a determining factor for the failure to recognize palliative care as a field of medicine specialization ${ }^{31}$. Moreover, there is a need and the desire to minimize the value of palliative care within the healthcare model geared more towards the curing of disease than care for the patient, which also contributes to the failings of this area ${ }^{31}$.

The lack of training and specialization of the teaching staff also emerged as an obstacle:

\begin{abstract}
"There is a lack of professors who specialize in palliative care. That's a fact. You need a teacher who specializes in palliative care but who has medical skills, or in other words someone who has a "bedside manner" but at the same time knows how to teach. Because it's no use just teaching without a bedside manner or having a bedside manner and not knowing how to teach. So this combination is a very important part of the development of the topic." (I6).
\end{abstract}

"Yes, because how can someone (a professional without training in palliative care) show that it's important, if they don't have this training." (I7).

This barrier to the development of palliative care has also been reported in other countries where there a lack of coordination and integration of services and a shortage of qualified professionals in palliative care was identified, with the latter resulting from a lack of educational and training programs ${ }^{30}$. An alternative, in the short and medium term, is the definitive implementation of palliative medicine in the curricula of medical schools ${ }^{22}$.

The category Challenges for the implementation of the proposal also included questions of bureaucracy and even the educational scope of more conservative schools. The majority of respondents gave objective answers such as: yes or totally without further details, with their responses accompanied by facial expressions of stress and attempts to change the subject, which could suggest some fear in relation to the subject. Some mentioned the possibility of circumventing the issue:

"Bureaucracy exists, but we can deal with it if we have the will.” (I6).
In a recent study, the students themselves recognized the deficiency of medical teaching in a discipline that deals with issues related to the process of death so that they do not have to learn alone or in an unsuitable manner in the future when dealing with this kind of patient ${ }^{32}$. There is therefore a need to create space to increase awareness and discussion of the topic of death in the training of health professionals, considering that they must deal with the issue in their daily activities ${ }^{32}$.

The following statements addressed the lack of space in the curricula to deal with the topic of palliative care:

"I think we need more time for them to learn about the subject. Sometimes it's not just palliative care, there are clinical topics that they only have a month to learn about. Often it's not enough." (I4).

"The curriculum is really full, but I think medical
course administrators use this more as an excuse
than a real reason. It is full, but there is a lot
of repeated content, a lot of content that could
be rearranged. What is really lacking is the
understanding of how this could help the student
from the beginning to the end of the course." (I6).

In terms of resistance among the management and educators of more traditional medical schools regarding the creating of space for areas such as palliative care, an important resolution would be the constant participation of such individuals in discussion forums on the reorientation of medical training in Brazil, such as the Brazilian Congress of Medical Education (COBEM) and the regional events of the Brazilian Association of Medical Education (ABEM), especially as ABEM has already emphasized the need for students to be properly trained in palliative care ${ }^{33}$.

Consistent with the aim of this study, a recent publication involving several researchers and professionals with experience in palliative care in Latin America, outlined some recommendations for the teaching of the discipline in primary care. According to this publication, at the end of their courses, students should be able to: acquire basic communication skills, apply principles of bioethics related to palliative care, understand basic definitions and principles in palliative care, possess basic 
knowledge of palliative care, assess patients and recognize the importance of teamwork ${ }^{34}$.

As the demand for the treatment of chronic diseases among the population is likely to increase, there is a need for comprehensive care to maintain the health of the population, as well as investment in the training of health professionals. In Brazil, a number of initiatives have considered the possibility of building a network of end-of-life care within the Unified Health System, such as the implementation of Advanced Oncology Centers, through palliative care teams which also include family support ${ }^{35}$. However, for now there are few palliative care services linked to specialized hospitals. It has already been found in a number of countries that Primary Health Care is the best level of care for the provision and coordination of palliative care for users ${ }^{35}$. It is therefore necessary to focus the training of professionals on the demands that will they will face when performing activities in Primary Health Care, and to configure competencies based on the challenges they will face in the future.

In summary, Chart 2 shows the final suggested competencies in palliative care to be acquired by students during undergraduate medical courses, divided into modules. The italicized items correspond to the changes and additions made by the experts in the area following the interviews conducted by the researcher.

Chart 2. Final suggestion of competencies in palliative care for undergraduate courses in Medicine. Natal, Rio Grande do Norte, 2017.

Competencies in palliative care to be acquired by students in undergraduate courses in Medicine.

Module I - Basic principles of palliative care - Students should be able to:

- Understand and apply the definitions, principles and indications of palliative care.

- To know the geographical distribution of palliative care services in Brazil.

- Perform patient care in palliative care and develop a care plan.

- Understand, apply and judge the communication of bad news in palliative care.

- Understand and belp to operationalize the operation of palliative care services.

Module II - Managing symptoms - Students should be able to:

- Evaluate pain, minimally use pharmacological treatment and indicate the proper non-pharmacological treatment.

- Evaluate dyspnea, coughing, nausea, vomiting, constipation, diarrhea, depression, insomnia and propose appropriate treatment.

- Evaluate delirium, anxiety, fatigue, oral bealth and provide for a more overall treatment.

- Understand and technically apply bypodermoclysis.

- Understand and apply continuation or not of nutrition in palliative care.

- Understand and provide care in controlling the symptoms of major emergencies in palliative care.

- Infer the applicability of palliative care in different specialties (Geriatrics, Pediatrics, Oncology, Family and Community Medicine, Pulmonology, Cardiology, Gastroenterology, Rheumatology, Nephrology, Anesthesiology, Neurology. Hematology and other medical specialties) and refer cases appropriately.

Module III - Teamwork - The student should be able to:

- Iudge and conceive in the future the dynamics of interprofessional relations in their day to day work.

- Understand and participate in teamwork, emphasizing their role in total suffering.

Module IV - Ethical and legal issues - Students should be able to:

- Estimate the importance of Brazilian legislation in the historical process of consolidation of palliative care.

- Differentiate concepts in bioethics, contrasting the various practical situations that exist.

- Employ the anticipated will directives in the reality of the patient.

Module V - Care in the last moments of life - The student should be able to:

- Guide the patient's last 48 hours of life and provide care in the last moments of life.

- Understand the definition of palliative sedation and palliative extubation, as well as when to use them.

- Detect and develop knowledge about patient, family and team anticipatory grief.

- Evaluate the perspective of terminality in different religions, developed through clinical practice. 
The main limitations of this study are the need to involve professionals with more experience in curriculum design and the difficulty interviewees experienced in distancing themselves from their role as specialists and focusing on the needs of undergraduate palliative care training.

\section{CONCLUSION}

We believe that the competencies suggested here are appropriate for the reality of each course, whether traditional, based on active methodologies, as a single curricular component, or inserted in several components of the course.

\section{REFERENCES}

1. Burlá C, Py L. Cuidados paliativos: ciência e proteção ao fim da vida. Cad Saúde Pública. 2014,30(6):1-3.

2. Forbes K, Gibbins J. Teaching and training in palliative medicine. In: Cherny N, Fallon M, Kaasa S, Portenoy R, Currow DC. Oxford textbook of palliative medicine. $5^{a}$ ed. Great Britain: Oxford university press; 2015. p. 146-53.

3. Elsne F, Centeno C, Cetto G, Conno F, Ellershaw J, Eychmuller S, et al. Recommendations of the European Association for Palliative Care (EAPC) for the development of undergraduate curricula in palliative medicine at European Medical Schools [Internet]. [place unknown]: EAPC; 2013 [acesso em 15 jan. 2017]. Disponível em: http://www. eapcnet.eu/LinkClick.aspx?fileticket=S1MItuIutQ\%3d\&tabid=1717

4. Societé Canadienne des Médecins de Soins Palliatifs. Former les futurs médecins dans les soins palliatifs et de fin de vie [Internet]. Suíte: SCMSP; 2008 [acesso em 15 jan. 2017]. Disponível em: https://www.cspcp. $\mathrm{ca} /$ information/efppec-competencies/

5. Kizawa Y, Tsuneto S, Tamba K, Takamiya Y, Morita T, Bito S, et al. Development of a nationwide consensus syllabus of palliative medicine for undergraduate medical education in Japan: a modified Delphi method. Palliat Med. 2012;26(5):744-52.

6. Paes P, Wee B. A Delphi study to develop the Association for Palliative Medicine consensus syllabus for undergraduate palliative medicine in Great Britain and Ireland. Palliat Med. 2008;22(1):360-4.
In order to teach and implement skills in palliative care in undergraduate education, however, it is vital that educators, public authorities, managers and medical students perceive this topic as essential, since the aging of the population and the increase of the prevalence of chronic diseases will increase the demand for such care in society.

The improvement of the essential competencies in palliative care suggested in this study should be discussed at forums of medical education and health professions to achieve more clarity about what is really necessary for the training of general practitioners.

7. Pastrana T, Wenk R, Lima L. Consensus-based palliative care compentencies for undergraduate nurses and physicians: a demonstrative process with Colombian Univesities. J Palliat Med. 2016;19(1):76:82.

8. Figueiredo MGMCA. O Estudo da morte e dos cuidados paliativos: uma experiência didática no currículo de medicina. Rev Bras Educ Med. 2013;37(2)298-307.

9. Horowitz R, Gramling R, Quill T. Palliative care education in US medical schools. Med Educ. 2014;48(1):59-66.

10. Bardin L. Análise de conteúdo. Lisboa: Edições 70; 2016.

11. Galera SC, Costa EFA, Pereira SRM, Rodrigues NL. Diretrizes da sociedade brasileira de geriatria e gerontologia sobre conteúdo de disciplinas: Módulos relacionados ao envelhecimento (geriatria e gerontologia) nos cursos de medicina. Rev Bras Geriatr Gerontol. 2014;8(3):192-5.

12. Kang J, Kim Y, Yoo YS, Choi JY, Koh SJ, Jho HJ, et al. Developing competencies for multidisciplinar hospice and palliative care professionals in Korea. Support Care Cancer. 2013;21(10):2707-17.

13. Lehto J, Hakkarainen K, Kellokumpu-Lehtinen P, Saarto T. Undergraduate curriculum in palliative medicine at Tampere University increases students' knowledge. BMC Palliat Care. 2017;16(13):1-9.

14. Carvalho RT, Parsons HA. Manual de cuidados paliativos ANCP. $2^{a}$. ed. Porto Alegre: Meridional Ltda; 2012. 
15. Palliative Care Curriculum for Undergraduates, Australian Government Department of Health [Internet]. Core Modules. Brisbane: PCC4U; 2013 [acesso em 15 jan. 2017]. Disponível em: http://www. pcc4u.org/learning-modules/core-modules/

16. Arnold R, Billings JA, Block S, Goldstein N, Morrison L, Okon T, et al. Hospice and Palliative Medicine Core Compentencies version 2.3 [Internet]. [place unknown]: American Academy of Hospice and Palliative Medicine; 2009 [acesso em 15 jan. 2017]. Disponível em: http://aahpm.org/uploads/education/ competencies/Competencies\%20v.\%202.3.pdf

17. Sá-Silva JR, Almeida CD, Guindani JF. Pesquisa documental: pistas teóricas e metodológicas. Rev Bras Hist Ciênc Soc. 2009;1(1):1-15.

18. Adams NE. Bloom's taxonomy of cognitive learning objectives. J Med Libr Assoc. 2015;103(3):152-3.

19. Palinkas LA, Horwitz SM, Green CA, Wisdom JP, Duan N, Hoagwood K. Purposeful sampling for qualitative data collection and analysis in mixed method implementation research. Adm Policy Ment Health. 2015;42(5):533-44.

20. Donnelly M, Martin D. History taking and physical assessment in holistic palliative care. Br J Nurs. 2016;25(22):1250-5.

21. Oliveira JR, Ferreira AC, Rezende NA, Castro LP. Reflexões sobre o ensino de bioética e cuidados paliativos nas escolas médicas do Estado de Minas Gerais, Brasil. Rev Bras Educ Med. 2016;40(3):364-73.

22. Brugugnoli ID, Gonsaga RAT, Silva EM. Ética e cuidados paliativos: o que os médicos sabem sobre o assunto? Rev Bioét. 2013;21(3):477-85.

23. Parikh PP, White MT, Buckingham L, Tchorz KM. Evaluation of palliative care of training and skills retention by medical students. J Surg Res. 2017;211(1):172-7.

24. Slort W, Blankenstein AH, Deliens L, Van der Horst HE. Facilitators and barriers for GP-patient communication in palliative care: a qualitative study among GPs, patients, and end-of-life consultants. Br J Gen Pract. 2011;61(585):167-72.

25. Aubry R. Pour une reforme en profondeur de l'enseignement de soins palliatifs et l'accompagnement. Med Palliat. 2011;10(3):107-8.
26. Costa MV, Vilar MJ, Azevedo GD, Reeves S. Interprofessional education as an approach for reforming health professions education in Brazil: emerging findings. J Interprof Care. 2014;28(4):379-80.

27. Incontri D. Equipes interdisciplinares em cuidados paliativos: religando o saber e o sentir. In: Santos FS. Cuidados paliativos: diretrizes, humanização e alívio de sintomas. São Paulo: Atheneu; 2011. p. 141-8.

28. Silveira MH, Cianpone MHT, Gutierrez BAO. Percepção da equipe multiprofissional sobre cuidados paliativos. Rev Bras Geriatr Geront. 2014;17(1):7-16.

29. Head B, Schapmire T, Earnshaw L, Faul A, Hermann C, Jones C, et al. Evaluation of an Interdisciplinary Curriculum Teaching Team-Based Palliative Care Integration in Oncology. J Cancer Educ. 2016;31(2):358-65.

30. Ellman MS, Schulman-Green D, Blatt L, Asher S, Viveiros D, Clark J, et al. Using online learning and interactive simulation to teach spiritual and cultural aspects of palliative care to interprofessional students. J Palliat Med. 2012;15(11): 1240-7.

31. Lynch T, Clark D, Centeno C, Rocafort J, Flores LA, Greenwood A, et al. Barriers to the development of palliative xare in the countries of Central and Eastern Europe and the Commonwealth of Independent States. J Pain Symptom Manage. 2009;37(3):305-15.

32. Moraes SAF, Kairalla MK. Avaliação dos conhecimentos dos acadêmicos do curso de Medicina sobre os cuidados paliativos em pacientes terminais. Einstein. 2010;8(2):162-7.

33. Zanolli MB, Maciel DT, Streit DS, Muraguchi EBO. "Internato Médico": Diretrizes Nacionais da ABEM para o internato no curso de graduação em medicina, de acordo com as Diretrizes Curriculares Nacionais. In: Lampert JB, Bicudo AM. 10 anos das Diretrizes Curriculares Nacionais dos cursos de graduação em Medicina. Rio de Janeiro: ABEM; 2014. p. 57-87.

34. Wenk R, Lima L, Mutto E, Berenguel MR, Centeno C. Encuentro sobre educación de cuidado paliativo en Latinoamerica. Recomendaciones sobre enzeñanza em el pregrado y en el primer nível de atención de salud. Med.Paliat. 2014;23(1):42-8.

35. Hennemann-Krause L, Freitas LA, Daflon PMN. Cuidados Paliativos e medicina de família e comunidade: conceitos e interseções. Rev Hosp Univ Pedro Ernesto. 2016;15(3):286-93. 